\title{
Simple and Sensitive Methods for the Determination of 2-(4'-Chloromethyl phenyl) Benzonitrile and 2-(4'-Bromomethyl phenyl) Benzonitrile Contents in Valsartan Drug Substance by Gas Chromatography
}

\author{
G. Amarnatha Reddy, ${ }_{1}^{1}$ K. Hussain Reddy, ${ }^{2}$ \\ M. Narendra Kumar, ${ }^{1}$ and Hemant kumar Sharma ${ }^{1}$ \\ ${ }^{1}$ Aurobindo Pharma Limited Research Centre-II, Survey No. 71\&72, Indrakaran Village, Sangareddy Mandal, \\ Medak, Andhra Pradesh 502 329, India \\ ${ }^{2}$ Department of Chemistry, Sri Krishnadevaraya University, Anantapur 515 003, India
}

Correspondence should be addressed to K. Hussain Reddy; khussainreddy@yahoo.co.in

Received 22 April 2013; Accepted 14 May 2013

Academic Editors: S. Babic, T. Bolanca, A. Niazi, and G. Vecchio

Copyright @ 2013 G. Amarnatha Reddy et al. This is an open access article distributed under the Creative Commons Attribution License, which permits unrestricted use, distribution, and reproduction in any medium, provided the original work is properly cited.

\begin{abstract}
Simple and reliable gas chromatographic methods were developed, optimized, and validated for the determination of 2-(4'chloromethyl phenyl) benzonitrile (2-CMPB) and 2-(4'-bromomethyl phenyl) benzonitrile (2-BMPB) contents in valsartan drug substance, using benzophenone as internal standard (IS). Efficient chromatographic separations were achieved on DB-1,30 m length with $0.53 \mathrm{~mm}$ i.d., and $3 \mu \mathrm{m}$ particle diameter column consists of $100 \%$ dimethyl polysiloxane as a stationary phase by passing helium as a carrier gas. The analytes were extracted in dichloromethane and monitored by flame ionization detector. The performance of these methods was assessed by evaluating specificity, precision, sensitivity, linearity, and accuracy. The limits of detection (LOD) and limits of quantification (LOQ) established for 2-CMPB are $0.10 \mu \mathrm{g} \mathrm{mL}^{-1}$ and $0.32 \mu \mathrm{g} \mathrm{mL}^{-1}$, respectively. For 2-BMPB, LOD is $0.31 \mu \mathrm{g} \mathrm{mL}^{-1}$ and LOQ is $0.95 \mu \mathrm{g} \mathrm{mL}^{-1}$. The average recoveries for 2-CMPB are in the range of $96.8 \%$ to $106.7 \%$ and for 2 -BMPB (LOQ level) are $99.3 \%$. The methods can be successfully applied for the routine analysis of valsartan drug substance.
\end{abstract}

\section{Introduction}

Valsartan belongs to a class of medicines known as angiotensin II receptor antagonist, which helps to control high blood pressure and congestive heart failure or postmyocardial infarction [1-4]. Chemically, valsartan is $\mathrm{N}$-(1-oxopentyl)-N[[2'-(1H-tetrazol-5-yl) [1,1'-biphenyl]-4-yl]methyl]-L-valine, having an empirical formula $\mathrm{C}_{24} \mathrm{H}_{29} \mathrm{~N}_{5} \mathrm{O}_{3}$ with a molecular weight of 435.5 . Valsartan is marketed under the trade name of Diovan [5] and is available as $40 \mathrm{mg}, 80 \mathrm{mg}, 160 \mathrm{mg}$, and $320 \mathrm{mg}$ tablets for oral administration. In the synthesis process of valsartan drug substance, 2 -( $4^{\prime}$-chloromethyl phenyl) benzonitrile (2-CMPB) and 2-( $4^{\prime}$-bromomethyl phenyl) benzonitrile (2-BMPB) were used as key raw materials. These residual organic raw materials may come through the manufacturing process. Based on structural alert, these raw materials come under genotoxic category. The maximum daily dosage of valsartan drug substance is $320 \mathrm{mg}$. As per threshold of toxicological concern (TTC) approach, these residual impurities should be less than $4.7 \mu \mathrm{gg}^{-1}$ [6-8]. Moreover, there is no specific information that is available in the literature on toxicity of these residual impurities confirming their carcinogenicity or mutagenicity. In the available literature many analytical procedures have been reported for the estimation of valsartan and its related substances [9-14]. A good number of analytical methods also reported for the determination of valsartan in combination of other drugs such as 
hydrochlorothiazide and amlodipine besylate in tablets [1517]. To the best of our knowledge, no report has been published on the analysis of 2-CMPB and 2-BMPB contents in valsartan drug substance. Hence, we trialed and successfully developed simple and reliable gas chromatographic (GC) methods with flame ionization detector for the determination of 2-CMPB and 2-BMPB contents in valsartan drug substance with sufficiently low levels of detection.

\section{Experimental}

2.1. Chemicals, Reagents, Samples, and Gases. Valsartan drug substances, 2-( $4^{\prime}$-chloromethyl phenyl) benzonitrile (2CMPB) and 2-( $4^{\prime}$-bromomethyl phenyl) benzonitrile (2$\mathrm{BMPB})$, are used. Analytical reagent (AR) grade benzophenone, dichloromethane, sodium hydroxide pellets, anhydrous sodium sulfate, and HPLC grade water were used. High purity gases, helium, hydrogen, zero air, and nitrogen, were used.

2.2. Gas Chromatography. All experiments were performed on Shimadzu GC 2010 gas chromatograph equipped with flame ionization detector and AOC-5000 autosampler with data handling system GC solutions/Empower Pro software. Agilent 7890A gas chromatograph aligned with flame ionization detector and CombiPal multipurpose autosampler with EZChrom software. Helium gas was used as a carrier gas. The analysis was carried on DB-1, $30 \mathrm{~m}$ long with $0.53 \mathrm{~mm}$ i.d., and $3.0 \mu \mathrm{m}$ particle diameter column consists of $100 \% \mathrm{dim}-$ ethyl polysiloxane as stationary phase (Agilent J\&W GC columns).

\subsubsection{The Chromatographic Conditions for the Determination} of 2-CMPB Method as Follows. The initial oven temperature of $150^{\circ} \mathrm{C}$ is maintained for $4 \mathrm{~min}$ and then increased to $230^{\circ} \mathrm{C}$ at a rate of $10^{\circ} \mathrm{C} / \mathrm{min}$, followed by holding at $230^{\circ} \mathrm{C}$ for $18 \mathrm{~min}$. The injection volume is $2 \mu \mathrm{L}$ with a split ratio set at $1: 1$. Helium is used as the carrier gas with a constant pressure of $75 \mathrm{kpa}$. The injector and detector temperatures are set at $250^{\circ} \mathrm{C}$ and $260^{\circ} \mathrm{C}$, respectively. The acquisition time was $30 \mathrm{~min}$. The retention times of the benzophenone and 2CMPB are about 10.0 and 16.0 minutes, respectively. Relative standard deviation for the ratio of peak area of 2-CMPB to the peak area of internal standard (benzophenone) for six injections of the standard solution is not more than $10.0 \%$.

\subsubsection{The Chromatographic Conditions for the Determination} of 2-BMPB Method as Follows. The initial oven temperature of $180^{\circ} \mathrm{C}$ is maintained for $0 \mathrm{~min}$ and then increased to $220^{\circ} \mathrm{C}$ at a rate of $10^{\circ} \mathrm{C} / \mathrm{min}$, followed by holding at $220^{\circ} \mathrm{C}$ for $26 \mathrm{~min}$. The injection volume is $2 \mu \mathrm{L}$ with a split ratio set at $2: 1$. Helium is used as the carrier gas with a constant pressure of $70 \mathrm{kpa}$. The injector and detector temperatures are set at $200^{\circ} \mathrm{C}$ and $260^{\circ} \mathrm{C}$, respectively. The acquisition time was $30 \mathrm{~min}$. The retention times of the benzophenone and 2-BMPB are about 5.0 and 12.0, minutes respectively. Relative standard deviation for the ratio of peak area of 2-BMPB to the peak area of internal standard (benzophenone) for six injections of the standard solution is not more than $10.0 \%$.

\subsection{Standard and Sample Solutions}

2.3.1. Preparation of $1.5 \mathrm{~N}$ Sodium Hydroxide Solution. Dissolve $6.0 \mathrm{~g}$ of sodium hydroxide pellets into a $100 \mathrm{~mL}$ of volumetric flask, add about $50 \mathrm{~mL}$ of water, dissolve by shaking, and then make up to volume with water.

2.3.2. Preparation of Internal Standard Solution (IS) for Determination of Both 2-CMPB and 2-BMPB. Accurately weigh and transfer about $0.024 \mathrm{~g}$ of benzophenone into a $50 \mathrm{~mL}$ volumetric flask, add $25 \mathrm{~mL}$ of dichloromethane to dissolve and make up to volume with dichloromethane. Dilute $1.0 \mathrm{~mL}$ of this solution to $500 \mathrm{~mL}$ with dichloromethane.

2.3.3. Preparation of Blank Solution. Into a clean and dry separating funnel, add $4 \mathrm{~mL}$ of $1.5 \mathrm{~N}$ sodium hydroxide solution and $3 \mathrm{~mL}$ of internal standard solution, and shake vigorously for $1 \mathrm{~min}$. Allow the two phases to separate, and collect the lower layer (dichloromethane) passed through anhydrous sodium sulfate.

\subsubsection{Standard Solutions}

(1) Preparation of Standard Stock Solution for 2-CMPB. Accurately weigh and transfer about $0.0245 \mathrm{~g}$ of 2 -CMPB reference standard into a $25 \mathrm{~mL}$ clean, dry volumetric flask, add $15 \mathrm{~mL}$ of internal standard solution, and dissolve and make up to volume with internal standard solution. Dilute $2 \mathrm{~mL}$ of this solution to $25 \mathrm{~mL}$ with internal standard solution. Further, dilute $1 \mathrm{~mL}$ of this solution to $50 \mathrm{~mL}$ with internal standard solution.

(2) Preparation of Standard Stock Solution for 2-BMPB. Accurately weigh and transfer about $0.0196 \mathrm{~g}$ of 2-BMPB reference standard into a $50 \mathrm{~mL}$ clean, dry volumetric flask, add $25 \mathrm{~mL}$ of internal standard solution, and dissolve and make up to volume with internal standard solution. Dilute $1 \mathrm{~mL}$ of this solution to $10 \mathrm{~mL}$ with internal standard solution. Further, dilute $2 \mathrm{~mL}$ of this solution to $50 \mathrm{~mL}$ with internal standard solution.

(3) Preparation of Standard Solution for Both 2-CMPB and 2-BMPB. Into a clean and dry separating funnel, add $4 \mathrm{~mL}$ of $1.5 \mathrm{~N}$ sodium hydroxide solution and $3 \mathrm{~mL}$ of $2-\mathrm{CMPB} /$ 2-BMPB standard stock solution and shake vigorously for $1 \mathrm{~min}$. Allow the two phases to separate, and collect the lower layer (dichloromethane) passed through anhydrous sodium sulfate.

2.3.5. Preparation of Sample Solution. Accurately weigh and transfer about $1.0 \mathrm{~g}$ of sample into a clean, dry separating funnel, add $4 \mathrm{~mL}$ of $1.5 \mathrm{~N}$ sodium hydroxide solution, and shake to dissolve the sample. Added $3 \mathrm{~mL}$ of internal standard solution and shaken vigorously for $1 \mathrm{~min}$. Allow the two phases to separate, and collect the lower layer (dichloromethane) passed through anhydrous sodium sulfate. 


\section{Results and Discussion}

3.1. Method Development and Optimization. The objective of this work is to determine low-level concentrations of 2-CMPB and 2-BMPB in valsartan drug substance by using gas chromatography (GC) system. In the synthesis process of valsartan drug, 2-(4'-chloromethyl phenyl) benzonitrile (2-CMPB) and 2-(4'-bromomethyl phenyl) benzonitrile (2BMPB) were used as key raw materials. Because of high boiling point of 2-CMPB and 2-BMPB, it is not easy to develop by head space gas chromatograph. Method development was initiated with valsartan, 2-CMPB and 2-BMPB solubility, miscibility, and extraction studies. Trial experiments were conducted to optimize the suitable solvent for extraction. Dichloromethane was finalized with $1.5 \mathrm{~N}$ sodium hydroxide solution. Hence, direct liquid injection method was adopted to develop 2-CMPB and 2-BMPB contents with liquid-liquid extraction. From few experimental trials, longer retention times, broad peak shapes, and interference were observed. These problems were rectified and optimized by using DB-1, $30 \mathrm{~m}$ long with $0.53 \mathrm{~mm}$ i.d., and $3.0 \mu \mathrm{m}$ particle diameter column consisted of $100 \%$ dimethyl polysiloxane as stationary phase, and carrier gas was helium.

Finally, satisfactory separation with better peak shapes was achieved, on chromatographic conditions which have been mentioned in gas chromatography (GC), and was used for validation study to evaluate its performance characteristics.

3.2. Method Validation. In order to determine the contents of 2-CMPB and 2-BMPB in valsartan drug substance, the methods were validated as per the ICH guidelines [18].

3.2.1. Specificity. To establish the specificity of both methods, valsartan drug, valsartan drug spiked with 2-CMPB/2$\mathrm{BMPB}$, and valsartan drug spiked with 2-CMPB/2-BMPB including all other residual solvents which are used in the synthesis process of valsartan drug substance and individual RT solutions were subjected to GC with FID to their respective methods. No interference was found at the retention of benzophenone and 2-CMPB/2-BMPB. The identity and specificity of 2-CMPB/2-BMPB and benzophenone were demonstrated with better separation of all other impurities.

3.2.2. Limit of Detection and Limit of Quantification (LOD and $L O Q$ ). The LOD and LOQ values for 2-CMPB and 2-BMPB were determined by $S / N$ ratio. The minimum concentration at $3.3: 1 \mathrm{~S} / \mathrm{N}$ was considered as detection limit, and the concentration at $10: 1 \mathrm{~S} / \mathrm{N}$ was established as quantification limit. A solution containing 2-CMPB and 2-BMPB was prepared around its quantification limit and detection limit concentrations, and it injected six replicates in their respective methods. The relative standard deviation [\% RSD $(n=6)$ ] for LOQ precision of 2-CMPB and 2-BMPB is 3.2 and 5.2 and for LOD precision 5.2 and 6.8, respectively. Overlay chromatograms of LOQ solution with standard solution are shown in Figure 1. The achieved precised values were shown in Table 1.
TABLE 1: Statistical data of linearity, LOD/LOQ for 2-CMPB and 2BMPB.

\begin{tabular}{lcc}
\hline Statistical parameters & 2-CMPB & 2-BMPB \\
\hline Correlation coefficient & 0.9993 & 0.9995 \\
$\begin{array}{l}\text { Intercept } \\
\text { Residual standard on deviation }\end{array}$ & -0.009 & 0.0170 \\
response & 0.033 & 0.0101 \\
Slope & 1.065 & 0.4967 \\
Concentration range $\left(\mu \mathrm{g} \mathrm{mL}^{-1}\right)$ & $0.32-2.40$ & $0.95-2.38$ \\
Limit of detection $\left(\mu \mathrm{gL}^{-1}\right)^{\mathrm{a}}$ & 0.1 & 0.31 \\
$\begin{array}{l}\text { Limit of quantification }\left(\mu \mathrm{g} \mathrm{mL}^{-1}\right)^{\mathrm{a}} \\
\text { Precision for limit of detection } \\
\text { (\% RSD) }\end{array}$ & 0.32 & 0.95 \\
$\begin{array}{l}\text { Precision for limit of } \\
\text { quantification }(\% \mathrm{RSD})\end{array}$ & 5.2 & 6.8 \\
\hline
\end{tabular}

${ }^{a}$ Precised LOD and LOQ values.

3.2.3. Linearity. The linearity was evaluated by measuring area ratio for 2-CMPB with respect to benzophenone and 2-BMPB with respect to benzophenone over the range of $0.32 \mu \mathrm{g} \mathrm{mL}^{-1}$ to $2.40 \mu \mathrm{g} \mathrm{mL}^{-1}$ and $0.95 \mu \mathrm{g} \mathrm{mL}^{-1}$ to $2.38 \mu \mathrm{g} \mathrm{mL}^{-1}$, respectively. Six concentrations for 2-CMPB and five concentrations for 2 -BMPB were prepared across the range and injected each in single injection. The statistical parameters slope, intercept, residual standard on deviation response, and correlation coefficient values were calculated and shown in Table 1.

3.2.4. Accuracy. Accuracy of the method was validated through recovery experiments by spiking known amount of 2-CMPB at LOQ level, 50\%, 100\%, and 150\% levels (with respect to test concentration). Each preparation was analyzed in triplicate, and \% recovery was calculated. The \% recovery for 2-CMPB ranged from 96.8 to 106.7 , and the average $\%$ recovery of four levels (twelve determinations) was $102.3 \%$, whereas the average recovery for 2-BMPB at LOQ level (with respect to test concentration) was $99.3 \%$. The validated accuracy results are shown in Table 2.

3.2.5. Precision. 2-CMPB standard solution was injected in six replicates (system precision). The $\% \operatorname{RSD}(n=6)$ value obtained for the ratio of areas of 2-BMPB with respect to benzophenone was 0.9 . The method precision and ruggedness of the method were evaluated by performing the valsartan drug analysis in six replicates by using two different columns, different instruments, and different analysts on different days. This study was done to prove the compliance of different gas chromatographs.

For 2-BMPB, standard solution was injected in six replicates (system precision). The $\% \operatorname{RSD}(n=6)$ value obtained for the ratio of areas of 2-BMPB with respect to benzophenone was 1.2. The precision results are shown in Table 3.

3.2.6. Robustness. This study was performed by making small but deliberate variations in the method parameters. These parameters are varied by $\pm 10 \%$ of carrier gas flow, $\pm 2^{\circ} \mathrm{C}$ of 


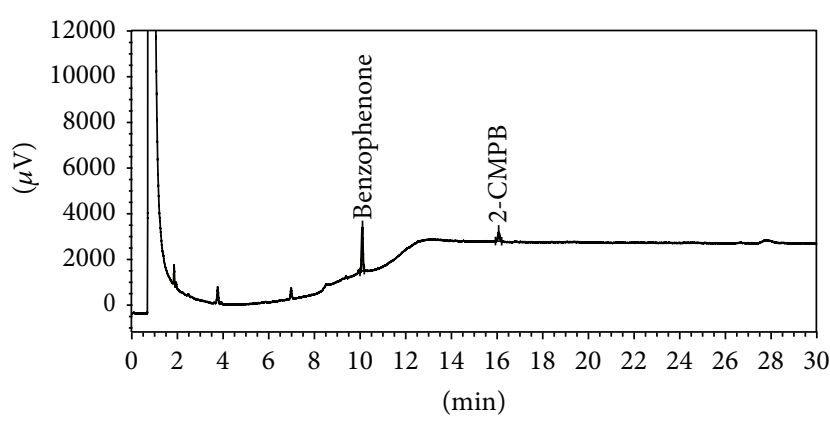

(a)

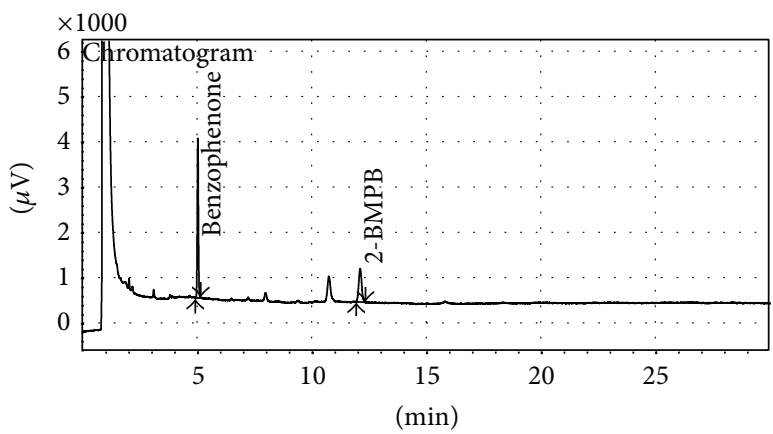

(c)

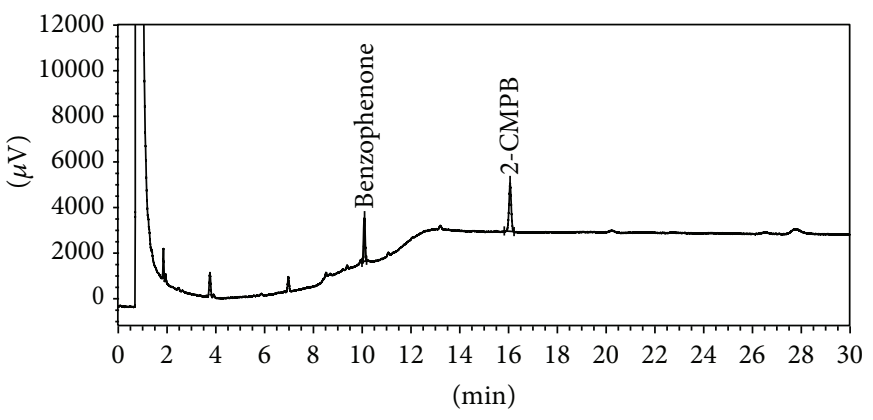

(b)

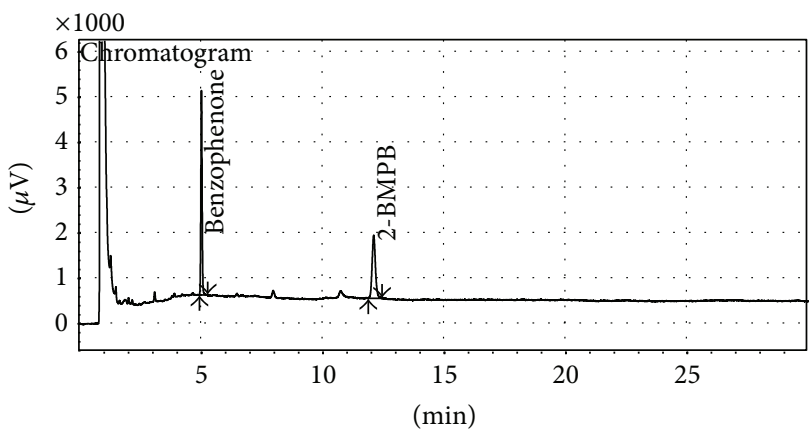

(d)

FIGURE 1: A typical representative overlaid GC chromatograms of (a) LOQ of 2-CMPB; (b) standard of 2-CMPB; (c) LOQ of 2-BMPB with (d) standard of 2-BMPB.

TABLE 2: Accuracy results of 2-CMPB and 2-BMPB.

\begin{tabular}{|c|c|c|c|c|c|}
\hline \multirow{2}{*}{ S. no } & \multicolumn{4}{|c|}{ 2-CMPB } & \multirow{2}{*}{$\begin{array}{c}\text { 2-BMPB } \\
\text { LOQ } \\
\text { level }\end{array}$} \\
\hline & $\begin{array}{l}\text { LOQ } \\
\text { level }\end{array}$ & $\begin{array}{l}50 \% \\
\text { level }\end{array}$ & $\begin{array}{l}100 \% \\
\text { level }\end{array}$ & $\begin{array}{l}150 \% \\
\text { level }\end{array}$ & \\
\hline Added $^{*}(\mu \mathrm{g} / \mathrm{g})$ & 0.95 & 2.47 & 4.96 & 7.43 & 2.84 \\
\hline Found $^{*}(\mu \mathrm{g} / \mathrm{g})$ & 0.92 & 2.57 & 5.29 & 7.54 & 2.82 \\
\hline Recovery (\%) & 96.8 & 104.0 & 106.7 & 101.5 & 99.3 \\
\hline$\% \mathrm{RSD}^{*}$ & 2.7 & 2.0 & 0.3 & 1.1 & 3.4 \\
\hline $\begin{array}{l}\text { Average } \\
\text { recovery** }\end{array}$ & \multicolumn{4}{|c|}{102.3} & - \\
\hline
\end{tabular}

${ }^{*}$ Average of 3 replicates.

${ }^{* *}$ Average recovery of four levels.

initial column oven temperature and $\pm 2^{\circ} \mathrm{C} / \mathrm{min}$ of ramp column oven temperature for the determination of 2-CMPB. In each robustness condition, solutions of blank, standard, and valsartan drug spiked with 2-CMPB were prepared and injected into GC to confirm the retention times. There is no much variation in the relative retention time (RRT) of 2-CMPB obtained at different deliberately varied robustness conditions from the developed methodology. Hence, the proposed method is robust.

\section{Conclusion}

The static GC methods described in this investigation were proved to be an ideal tool for the determination of 2-CMPB
TABLE 3: Precision results of 2-CMPB and 2-BMPB.

\begin{tabular}{lccccc}
\hline & \multicolumn{2}{c}{ 2-CMPB } & & \multicolumn{2}{c}{ 2-BMPB } \\
S. no. & $\begin{array}{c}\text { System } \\
\text { precision } \\
\text { (area ratio) }\end{array}$ & $\begin{array}{c}\text { Method } \\
\text { precision } \\
(\mu \mathrm{g} / \mathrm{g})\end{array}$ & $\begin{array}{c}\text { Ruggedness } \\
(\mu \mathrm{g} / \mathrm{g})\end{array}$ & $\begin{array}{c}\text { System } \\
\text { precision } \\
\text { (area ratio) }\end{array}$ & $\begin{array}{c}\text { Method } \\
\text { precision } \\
(\mu \mathrm{g} / \mathrm{g})\end{array}$ \\
\hline 1 & 1.318 & 5.28 & 4.82 & 0.785 & 4.96 \\
2 & 1.331 & 5.31 & 4.87 & 0.789 & 4.46 \\
3 & 1.309 & 5.28 & 5.09 & 0.779 & 4.63 \\
4 & 1.334 & 5.30 & 5.08 & 0.762 & 4.38 \\
5 & 1.312 & 5.24 & 4.95 & 0.778 & 4.67 \\
6 & 1.306 & 5.25 & 4.96 & 0.783 & 4.40 \\
\hline Avg. & 1.318 & 5.28 & 4.96 & 0.779 & 4.58 \\
SD & 0.01 & 0.03 & 0.11 & 0.01 & 0.220 \\
$\%$ & 0.9 & 0.5 & 2.2 & 1.2 & 4.8 \\
RSD & 0.9 & & & & \\
\hline
\end{tabular}

and 2-BMPB in valsartan drug substance at lower levels. Method validation data demonstrated that the developed methods are simple, sensitive, cost-effective, and accurate for the estimation of 2-CMPB and 2-BMPB. The method for the determination of 2-CMPB is robust to minor variations in the chromatographic parameters. The identity and specificity of 2-CMPB and 2-BMPB were well established in this method by GC with FID with moderate run time at very low levels. Hence, the proposed GC methods can be employed conveniently in the pharmaceutical laboratory for the routine quality control of 2-CMPB and 2-BMPB in valsartan drug substance. 


\section{References}

[1] S. Ghosh, A. S. Kumar, and G. N. Mehta, "A short and efficient synthesis of valsartan via a Negishi reaction," Beilstein Journal of Organic Chemistry, vol. 6, article 27, 2010.

[2] G. T. McInnes, “Clinical advantage of valsartan," Cardiology, vol. 91, no. 1, pp. 14-18, 1999.

[3] S. Oparil, S. Dyke, F. Harris et al., "The efficacy and safety of valsartan compared with placebo in the treatment of patients with essential hypertension," Clinical Therapeutics, vol. 18, no. 5, pp. 797-810, 1996.

[4] K. F. Croom and G. M. Keating, "Valsartan: a review of its use in patients with heart failure and/or left ventricular systolic dysfunction after myocardial infarction," American Journal of Cardiovascular Drugs, vol. 4, no. 6, pp. 395-404, 2004.

[5] http://www.rxlist.com/diovan-drug.htm.

[6] L. Müller, R. J. Mauthe, C. M. Riley et al., "A rationale for determining, testing, and controlling specific impurities in pharmaceuticals that possess potential for genotoxicity," Regulatory Toxicology and Pharmacology, vol. 44, no. 3, pp. 198-211, 2006.

[7] E. J. Delaney, "An impact analysis of the application of the threshold of toxicological concern concept to pharmaceuticals," Regulatory Toxicology and Pharmacology, vol. 49, no. 2, pp. 107124, 2007.

[8] K. L. Dobo, N. Greene, M. O. Cyr, S. Caron, and W. W. Ku, "The application of structure-based assessment to support safety and chemistry diligence to manage genotoxic impurities in active pharmaceutical ingredients during drug development," Regulatory Toxicology and Pharmacology, vol. 44, no. 3, pp. 282-293, 2006.

[9] B. M. Sudesh and K. S. Uttamrao, "Determination and validation of valsartan and its degradation products by isocratic HPLC," Journal of Chemical Metrology, vol. 3, no. 1, pp. 1-12, 2009.

[10] C. Krishnaiah, A. R. Reddy, R. Kumar, and K. Mukkanti, "Stability-indicating UPLC method for determination of Valsartan and their degradation products in active pharmaceutical ingredient and pharmaceutical dosage forms," Journal of Pharmaceutical and Biomedical Analysis, vol. 53, no. 3, pp. 483-489, 2010.

[11] A. Zarghi, A. Shafaati, S. M. Foroutan, and H. Movahed, "Rapid quantification of valsartan in human plasma by liquid chromatography using a monolithic column and a fluorescence detection: application for pharmacokinetic studies," Scientia Pharmaceutica, vol. 76, no. 3, pp. 439-450, 2008.

[12] N. Aslan, P. E. Erden, E. Canel, B. Zeybek, and E. Kiliç, "Potentiometric determination of valsartan in a pharmaceutical preparation and its protonation constants," Asian Journal of Chemistry, vol. 22, no. 5, pp. 4010-4016, 2010.

[13] D. U. Vinzuda, G. U. Sailor, and N. R. Sheth, "RP-HPLC method for determination of valsartan in tablet dosage form," International Journal of ChemTech Research, vol. 2, no. 3, pp. 1461-1467, 2010.

[14] D. G. Thomas Parambi, M. Mathew, and V. Ganesan, "A validated stability indicating HPLC method for the determination of Valsartan in tablet dosage forms," Journal of Applied Pharmaceutical Science, vol. 1, no. 4, pp. 97-99, 2011.

[15] K. Lakshmi and S. Lakshmi, "Simultaneous spectrophotometric determination of valsartan and hydrochlorothiazide by $\mathrm{H}$-point standard addition method and partial least squares regression," Acta Pharmaceutica, vol. 61, no. 1, pp. 37-50, 2011.
[16] U. Kullai Reddy, J. Sriramulu, P. Viswanath Reddy, and B. Varaprasad, "Single RP-HPLC method for the determination of Hydrochlorothiazide, Amlodipine besylate and Valsartan in pharmaceutical products," Journal of Pharmacy Research, vol. 4, no. 3, pp. 894-896, 2011.

[17] D. Tian, X. Tian, T. Tian, Z. Wang, and F. Mo, "Simultaneous determination of valsartan and hydrochlorothiazide in tablets by RP-HPLC," Indian Journal of Pharmaceutical Sciences, vol. 70, no. 3, pp. 372-374, 2008.

[18] International Conference on Harmonization of Technical Requirements for Registration of Pharmaceuticals for Human Use, ICH harmonized tripartite guideline, Validation of analytical procedures: Text and methodology, Q2(R1), step 4, 2005. 

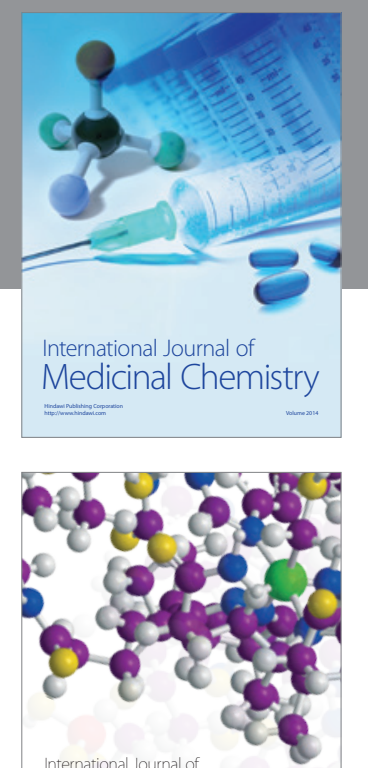

\section{Carbohydrate} Chemistry

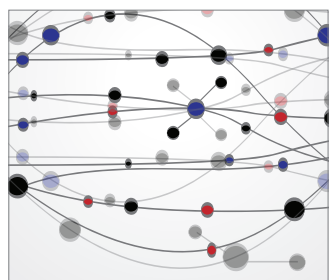

The Scientific World Journal
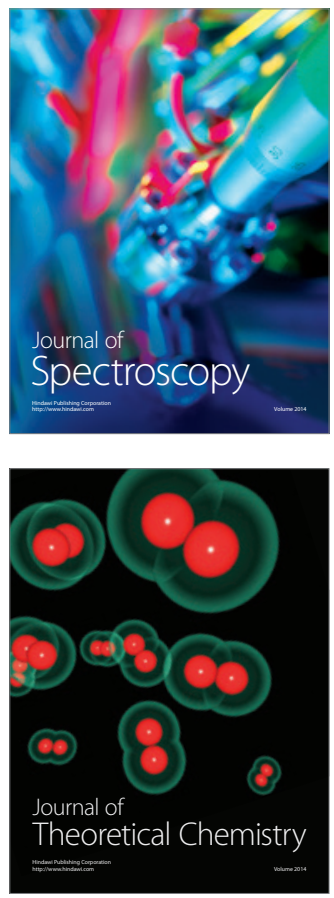
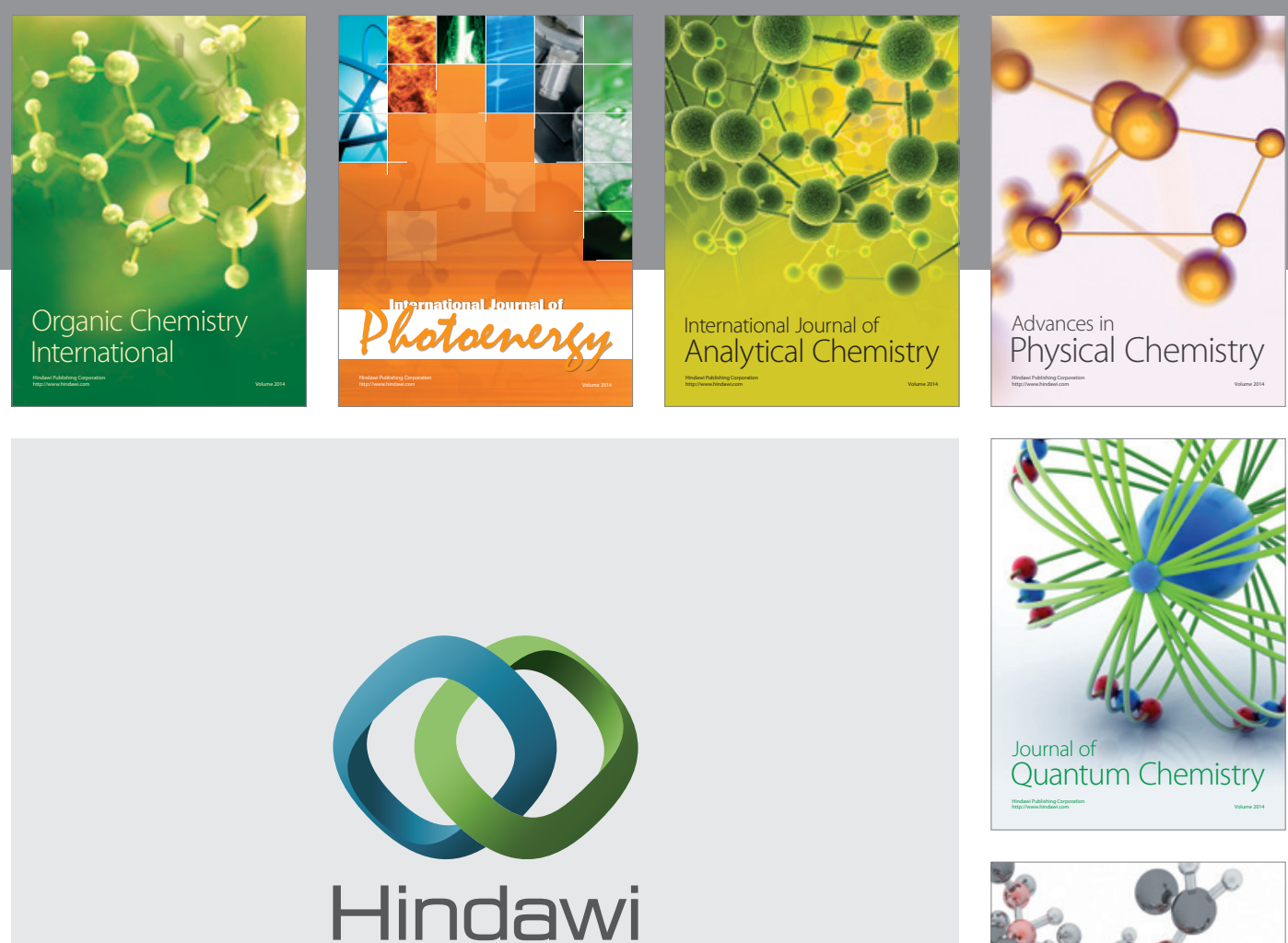

Submit your manuscripts at

http://www.hindawi.com

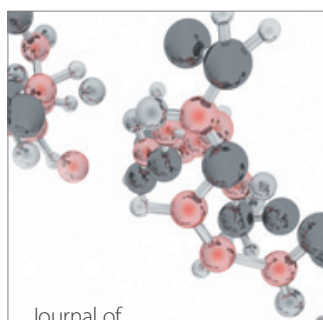

Analytical Methods

in Chemistry

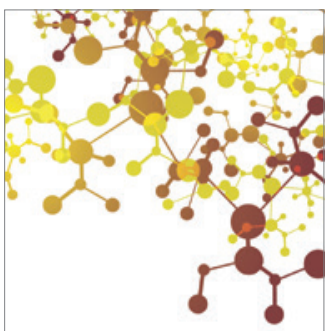

Journal of

Applied Chemistry

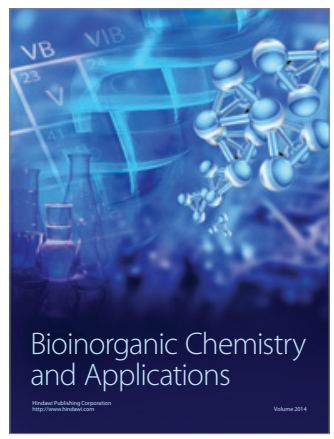

Inorganic Chemistry
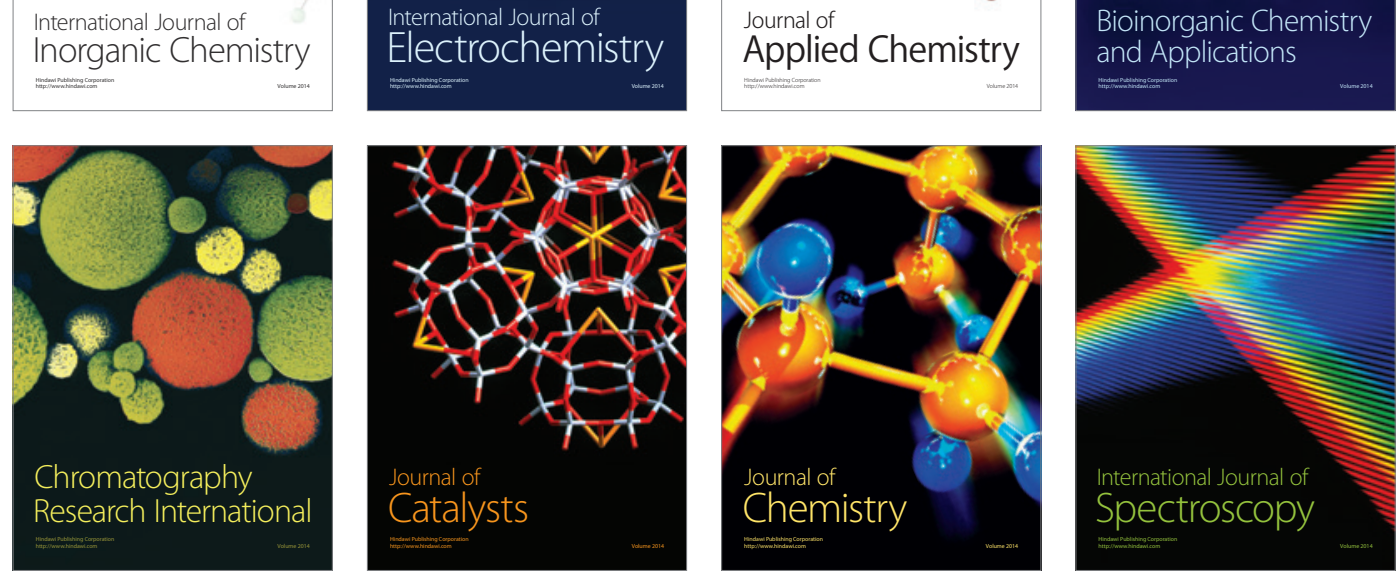